\title{
A produção de vôngole e seu potencial para o desenvolvimento de novos produtos a base de pescado
}

\section{The production of clams and its potential for development of new products based on fish.}

\author{
Mayla Monique dos Santos Leite ${ }^{1}$, Gesilene Mendonça Oliveira ${ }^{2}$
}

Resumo: A dificuldade em suprir a demanda de proteína de origem animal de excelente valor biológico para a população humana é uma das maiores preocupações do nosso século. De acordo com a FAO, a atividade pesqueira (pesca extrativa e aquicultura), será uma das principais atividades responsáveis pela segurança alimentar do planeta, com previsões de produção de proteína de origem animal para a próxima década maior do que o setor de animais de abate (carnes bovinas, suínas e aves). A utilização de recursos pesqueiros subutilizados com potencial para explotação poderá assegurar a manutenção da oferta primária de matéria prima no mercado interno local e/ou regional, e inibir oscilação de preços, como a prática da mariscagem. Neste contexto, o presente artigo de revisão tem por objetivo evidenciar o potencial da Anomalocardia brasiliana para explotação e processamento contribuindo para o fortalecimento desta cadeia produtiva no segmento artesanal e diversificação de produtos no mercado brasileiro.

Palavras-chave: Anomalocardia brasiliana ; Moluscos bivalves; Tecnologia de alimentos; Pesca extrativa.

\begin{abstract}
The difficulty in supplying the animal protein demand of great biological value for the human population is a major concern of our century. According to the FAO, the fishery (extractive fishing and aquaculture), will be one of the main activities responsible for food safety in the world, with animal protein production forecasts for the next decade longer than the slaughter of animals sector (beef, pork and poultry). The use of fishing resources with underutilized potential for exploitation can ensure the maintenance of primary supply of raw materials on-site domestic and / or regional, and inhibit movement of prices, as the practice of shellfish. In this context, the present review aims to highlight the potential of Anomalocardia brasiliana to exploitation and processing contributing to the strengthening of this production chain in the craft segment and product diversification in the Brazilian market.
\end{abstract}

Key words: Anomalocardia brasiliana ; Bivalve molluscs, Food technology, Mining and fishing.

\footnotetext{
*Autor para correspondência

Recebido para publicação em 20/04/2015; aprovado em 22/09/2015

${ }^{1}$ Mestranda do Programa de Pós-Graduação em Ciência e Tecnologia de Alimentos do Departamento de Tecnologia de Alimentos do Instituto de Tecnologia da Universidade Federal Rural do Rio de Janeiro- Seropédica- RJ. E-mail: maylaleite@ hotmail.com,

${ }^{2}$ Zootecnista, DsC, Prof. Adjunto do Departamento de Tecnologia de Alimentos do Instituto de Tecnologia da Universidade Federal Rural do Rio de Janeiro E-mail: gesilene@ufrrj.br
} 


\section{INTRODUÇÃO}

A produção de alimentos necessária para suprir a demanda por proteína de origem animal de excelente valor biológico para a população mundial é uma das maiores preocupações do nosso século. Relatórios da Food Agriculture Organization - FAO apontam o rápido crescimento demográfico mundial como um dos principais fatores que contribui para que a produção de alimentos proteicos aumente em todo planeta. Estimativas da FAO descrevem que em 2050 o contingente de pessoas atingirá cerca de 9.6 bilhões de indivíduos e de que é preciso garantir a segurança alimentar sem comprometer os recursos naturais renováveis e as gerações futuras.

A cadeia produtiva do pescado em nível mundial apresenta importância socioeconômica expressiva, tanto no que diz respeito à produção de alimento proteico de excelente valor biológico que possa garantir o acesso dessa fonte de proteína a população, quanto à geração de empregos (diretos e indiretos) e de divisas para o crescimento dos países costeiros, como o Brasil. De acordo com a FAO, a atividade pesqueira (pesca extrativa e aquicultura), será uma das principais atividades responsáveis pela segurança alimentar do planeta, com previsões de produção de proteína de origem animal para a próxima década maior do que o setor de animais de abate (carnes bovinas, suínas e aves).

No entanto, é de conhecimento que a atividade de pesca extrativista está subordinada ao meio natural e aos ciclos biológicos, as oscilações climáticas naturais que tornam difíceis as previsões de captura, dependência das reservas naturais de recursos pesqueiros e das espécies preferidas para o consumo (as de relevância econômica) e que nas últimas quatro décadas sua produção (nacional e mundial) encontra-se estagnada. Sabe-se também que toda esperança para atender a demanda de proteína animal tem sido depositada na aquicultura (cultivo de organismos aquáticos). Porém, a utilização de recursos pesqueiros subutilizados com potencial para explotação poderá assegurar a manutenção da oferta primária de matéria prima no mercado interno local e/ou regional, e inibir oscilação de preços, como por exemplo: a prática da atividade realizada pelo segmento artesanal, a mariscagem. Muitas famílias sustentam seus filhos e netos a partir da extração de duas espécies de moluscos bivalvos, os mexilhões (Perna perna) que apresenta importância econômica em nível nacional, e o vôngole (Anomalocardia brasiliana) de baixo valor comercial sendo considerado uma espécie subexplotada, em nível regional.

O beneficiamento da matéria prima é desempenhado pelo próprio catador ou marisqueiro empregando mão de obra familiar, sendo na maioria mulheres e crianças, e consistem basicamente no desconche, cozimento e acondicionamento do produto em sacos de polietileno.

A falta de unidades de processamento desses bivalvos faz com que o produto seja basicamente fornecido a população na sua forma in natura ou pré-cozida resfriada e/ou congelada, o que não potencializa o consumo e acaba tornando-se um entrave a comercialização dos bivalvos produzidos. Além de ser preocupante devido ao uso inadequado de técnicas de processamento e manipulação, refletindo sobre a qualidade do produto final, tanto do ponto de vista nutricional quanto microbiológico.

Outra forma para estimular consumo e consequentemente aumentar a demanda é agregar valor aos produtos derivados do pescado marinho de baixo valor comercial capturado pelo segmento artesanal. Uma das vantagens em aplicar um processamento é poder apresentá-los de forma melhor aceita que a tradicional, reduzir perdas e a contaminação por microrganismos devido à manipulação inadequada, além de estender o prazo de vida útil.

Neste contexto, esta revisão tem por objetivo evidenciar o potencial de explotação e processamento do vôngole, visando contribuir para o fortalecimento desta cadeia produtiva no segmento artesanal, e diversificação de produtos a base de vôngole no mercado brasileiro além de agregar valor econômico e rentabilidade aos marisqueiros e/ou catadores artesanais do segmento artesanal.

\section{REVISÃO BIBLIOGRÁFICA}

\section{Produção Mundial e Nacional de Pescado: tendências atuais}

A produção de pescado no mundo atingiu no ano de 2012 um montante de 158 milhões de toneladas (t). A pesca extrativa (marinha e continental) contribuiu com um pouco mais de 91 milhões de $\mathrm{t}$ e a aquicultura (marinha e continental) contribuiu com cerca de 66,6 milhões de $\mathrm{t}$. Ambas as atividades apresentam relevante cunho social e econômico e nas últimas quatro décadas vem mantendo as tendências previstas, onde a pesca extrativa ou de captura apresenta-se estagnada, sendo impossível retirar a cada ano rendimentos maiores e a aquicultura mantendo sua ascensão no mercado internacional e nacional, sendo considerada pela FAO a principal responsável pela segurança alimentar do planeta (FAO, 2012; FAO, 2014).

A China $(37,69 \%)$, a Indonésia $(6,93 \%)$ e a Índia $(5,55 \%)$ lideram o ranking mundial na produção total de pescado. O Brasil ocupando a $19^{\circ}$ posição, cuja produção correspondeu a 0,75\% da produção mundial (BRASIL, 2013). Nas modalidades de pesca extrativa e aquicultura temos o mesmo panorama. Para pesca extrativa a China (17,50\%), Indonésia $(6,02 \%)$ e Índia $(5,25 \%)$ ocupando as treis primeiras colocações e o Brasil ocupando a $25^{\circ}(0,88 \%)$ posição. E na aquicultura, destacando-se mais uma vez a China $(60,9 \%)$, Indonésia $(6,59 \%)$, Índia $(5,89 \%)$ e o Brasil na $17^{\circ}$ posição no ranking mundial (BRASIL, 2013).

No Brasil a produção de pescado no ano de 2011 atingiu 1.431.974,4 t, o que representou um aumento de aproximadamente $13,2 \%$ quando comparada com a produção em 2010 (BRASIL, 2013). Quanto às modalidades de pesca, a pesca extrativa marinha representou a maior parte da produção, com $38,7 \%$ do total produzido no país; seguida pela aquicultura continental com 38\%; pesca extrativa continental com $17,4 \%$ e aquicultura marinha com aproximadamente $6 \%$.

A região Nordeste foi a maior produtora com 31,7\%, em seguida temos a região Sul com $23,5 \%$, depois a região Norte com 22,8\% e Sudeste e Centro-Oeste com 15,8\% e $6,2 \%$, respectivamente. Todas as regiões brasileiras tiveram um incremento na produção de pescado em relação à produção no ano de 2010 (BRASIL, 2013).

Das espécies de relevância econômica no mercado nacional e internacional, o grupo dos peixes corresponderam a $87 \%$ da produção total de pescado, o grupo dos crustáceos a $10 \%$ e grupo dos moluscos a 3\% (BRASIL, 2013).

Em relação a balança comercial brasileira de pescado no período de 2011 as exportações alcançaram U\$\$ 
271.193.147 milhões de dólares e as importações corresponderam a U\$ 1.262.888.212 bilhões de dólares, havendo um déficit de quase U\$\$ 991 milhões (BRASIL, 2013).

Os principais produtos exportados na ordem decrescente de valores foram: lagostas congeladas (exceto inteiras) com 2.134.773 kg (U\$ 69.163.978), extratos e sucos com $1.873 .641 \mathrm{~kg}$ (U\$ 29.006.504) e peixes congelados com 7.422.285 kg (U\$ $\$ 22.426 .922$ ). Considerando as cifras, os Estados Unidos foi o maior comprador dos produtos de pescado brasileiros, seguido da Espanha, Japão, Hong Kong e França. Considerando a quantidade em toneladas, a Espanha fica em primeiro lugar, seguida dos Estados Unidos, Japão, China e França (BRASIL, 2013).

O pescado destinado à exportação no Brasil é transportado principalmente pela via marítima 80,78\%; em seguida utiliza-se a via aérea $12,06 \%$ e depois a via rodoviária com 7,06\%, estes dados foram referentes ao ano de 2007. Os principais portos envolvidos na exportação de pescado estão na região Nordeste: o de Fortaleza (CE), Recife (Suape) e Pecém (CE) (IBAMA, 2007). Considerando as importações brasileiras, os países que mais exportaram para o Brasil em relação ao valor em 2011 foram: Chile, China, Noruega, Argentina e Portugal. No entanto, em relação à quantidade em toneladas foram: China, Argentina, Chile, Noruega e Portugal. Os principais produtos importados pelo Brasil em ordem decrescente de valores foram: bacalhau, filés congelados e salmões (BRASIL, 2013).

\section{A Pesca Extrativa e a Produção de Bivalvos}

O Brasil é um país expressivamente agrícola, e neste contexto, a atividade pesqueira (pesca extrativa e aquicultura) se destaca por apresentar um importante cunho social e econômico para o nosso país. No ano de 2010 a atividade pesqueira gerou um PIB de 5 bilhões de reais, e o segmento artesanal contribuiu com $45 \%$ do montante produzido (1.264 toneladas) em nível nacional (MPA, 2012).

A produção de moluscos oriundos da pesca extrativa nos anos de 2008, 2009 e 2010 correspondeu a 13,303 t, 14,672 t e 13,858 t, respectivamente. No entanto, a maior representação e importância econômica são dadas aos moluscos bivalvos (mexilhões, ostras, vieiras, surururs e berbigões (estes também chamados de vôngoles), cuja produção no ano de 2010 pela pesca extrativa foi de $8.204 \mathrm{t}$ (BRASIl, 2013).

A produção de vôngoles no ano de 2010 estimada pela MPA foi de 57 t. A produção média anual ainda é modesta, mas a atividade é de importante cunho social e econômico para o litoral sul do estado do RJ, especialmente na Baía de Sepetiba, porque é geradora de alimento e empregos, atuando na complementação da renda de marisqueiros e/ou catadores artesanais contribuindo para a fixação das populações tradicionais em seus locais de origem.

Atualmente a pesca extrativa representa para as comunidades caiçaras do litoral sul fluminense uma fonte de trabalho e renda aliado à manutenção de sua cultura dirigida para o mar. Do mesmo modo, quando a atividade é desenvolvida com vistas à sustentabilidade pode contribuir para diminuição da pressão sobre os recursos naturais mais visados economicamente, como a pesca da sardinhaverdadeira e do atum.

\section{O Uso de Pescados na Alimentação Humana}

O homem utiliza o pescado como fonte de alimento desde tempos remotos, e ainda hoje é uma das quatro principais fontes de proteína consumida, contribuindo com cerca de $17 \%$ da quantidade de proteínas de origem animal ingerida pelo homem (FAO, 2014). Em países subdesenvolvidos o pescado representa a principal fonte de proteína de origem animal de populações ribeirinhas ou litorâneas (MPA, 2008). A carne contém proteínas de alto valor biológico, baixo teor de gordura, vitaminas, minerais e carboidratos, um alimento completo. Tais características desencadearam mudanças nos hábitos alimentares, por motivos de saúde, levando os consumidores a preferir as carnes brancas às vermelhas, colaborando para aumentar o consumo de peixes e seus produtos. As populações litorâneas apreciam esse tipo de alimento sendo comum encontrar em bares, restaurantes, hotéis e pousadas, pratos preparados à base de pescado. No entanto, é necessário destacar que em nível nacional o consumo de peixes, moluscos e crustáceos ainda é baixo (11 kg/pessoa/ano) quando comparado com a média mundial (19,2 kg/pessoa/ano) e a recomendada pela Organização Mundial da Saúde (12 kg/pessoa/ano) (MPA, 2014; FAO, 2012). Esse baixo consumo parece está associado à falta de hábito dos brasileiros em comer peixes e frutos do mar, a forma simples de apresentação do produto in natura que não potencializa o consumo e a falta de qualidade da matéria prima in natura devido à exigência da cadeia de frio (uso do gelo) para manutenção das suas características de frescor que estão relacionadas à manutenção da sua qualidade nutricional e sanitária para consumo (MPA, 2012). No município de Itaguaí e municípios vizinhos (Sepetiba, Mangaratiba, Angra dos Reis e Parati) a principal forma de apresentação, comercialização e consumo do pescado marinho é a in natura atendendo um mercado muito regional ou local e de forma sazonal dependendo da espécie alvo.

A utilização de recursos pesqueiros sem importância econômica ou subexplotados, como o vôngole, poderá assegurar a manutenção da oferta primária de matéria prima no mercado interno e inibir oscilação de preços no mercado. Assim como, a aplicação de técnicas de processamento, como produzir embutidos a base de bivalvos, é poder apresentá-los de forma melhor aceita que a tradicional, atingindo um mercado atualmente fechado ao produto na sua forma in natura, promovendo com êxito a diversificação de produtos com qualidade sensorial, estimulando consumo, gerando trabalho e renda, melhorando a qualidade de vida de marisqueiros e /ou catadores artesanais, através da agregação de valor aos produtos derivados, os fazendo enxergar a atividade como um empreendimento lucrativo e com a responsabilidade de produzir alimentos com qualidade nutricional e microbiológica para o consumo (BEIRÃO, 2000; GONÇALVES, 2011).

Do ponto de vista nutricional os bivalvos são considerados alimentos de excelente valor nutricional. A carne contém proteínas de alto valor biológico, baixo teor de gordura, vitaminas, minerais e carboidratos e glicogênio, sua principal forma de reserva energética (OGAWA; MAIA, 1999). O valor nutritivo da carne de bivalvos se reflete nos teores de proteína e gordura. O teor de proteína bruta fica em torno de $10 \%$ apresentando em sua composição um teor de aminoácidos essenciais completo e balanceado contribuindo para o alto valor biológico da dieta. A carne apresenta um baixo teor de gordura $(1,5 \%)$ e colesterol, com apenas cerca 
de 20 a $28 \%$ de calorias, em que os ácidos graxos mais frequentes são os polinsaturados (40 a $45 \mathrm{~g} .100 \mathrm{~g}^{-1}$ de porção comestível) e menos de $80 \mathrm{mg}$ de colesterol. $100 \mathrm{~g}^{-1}$ de carne. Essa composição apresenta grandes vantagens nutricionais porque essa gordura polinsaturada é fonte de ácidos graxos benéficos ao organismo humano, da serie ômega-3 (eicosapentaenoico-EPA e $\alpha$-linolênico) e ômega-6 (docosahexaenoico-DHA), além de assegurar uma melhor digestão e assimilação pelo organismo humano (DONG, 2001). Os efeitos benéficos do EPA e do DHA podem ser citados por prevenir desordens cardíacas e inflamatórias, a ateriosclerose e a trombose, além de agir na manutenção da pressão arterial, coagulação sanguínea, na formação de compostos que tem propriedades hormonais, no desenvolvimento e função do cérebro, retina e esperma. Por estas razões, a elaboração de pratos contendo moluscos pode ser considerada um alimento ideal para todos os tipos de dietas até mesmo para indivíduos que necessitem de uma dieta baixa em calorias (DONG, 2001).

No Brasil, os moluscos bivalvos apresentam uma ampla distribuição geográfica ocorrendo em toda América do Sul, sendo explotado, cultivado e consumido em regiões costeiras (AVELAR, 1998) As populações litorâneas apreciam esse tipo de alimento sendo comum encontrar em bares, restaurantes, hotéis e pousadas pratos preparados com moluscos. No entanto, é necessário destacar que em nível nacional o consumo é baixo e parece está associado à falta de hábito dos brasileiros em comer frutos do mar e a forma simples de apresentação do produto, in natura, o que não potencializa o consumo. Em nosso país a comercialização de bivalvos explotados e/ou cultivados é feita basicamente na forma in natura (fresco na concha) ou pré-cozida resfriada ou congelada (sem a concha) atendendo um mercado local e de forma sazonal. A produção de vôngole na baía de Sepetiba é modesta atendendo o mercado local, e quando o produto não é comercializado é consumido pelo próprio marisqueiro e sua família. Em países desenvolvidos, como a China, Espanha, Holanda e Nova Zelândia as espécies de relevância econômica, como os mexilhões e ostras, o cultivo industrial é um fato. E nestes países o consumo de moluscos industrializados é comum, principalmente nas formas defumada e enlatada (conserva), com exceção da indústria neozelandesa, que também comercializa esses bivalvos congelados na meia concha ou desconchado e congelado individualmente (Individually Quality Frozen - IQF). Além do aproveitamento de seus resíduos (as conchas) para fabricar botões, bijuterias e para fazer adubos e também na construção civil (HELM et al., 2004; FAO, 2009).

\section{Anomalocardia brasiliana:}

A Anomalocardia brasiliana (GMELIN, 1791) pertencente à família Veneridae que reúne aproximadamente 500 espécies viventes, pertencentes à aproximadamente 50 gêneros e 12 subfamílias (CANAPA et al., 1996).

A espécie possui valvas trigonais extremamente rígidas, levemente rostrada na sua parte posterior, lúnula bem impressa e sino palial pequeno (RIOS, 1994). Sua coloração varia entre amarelo vivo e branco podendo apresentar ou não pequenas faixas radiais de coloração roxa ou marrom que cobre todas as valvas do indivíduo (SOUZA, 2007). A espécie é conhecida vulgarmente por diferentes nomes como "berbigão", "sarro de pito", "mija-mija" ou "vôngole" (NARCHI, 1972). No Brasil, regiões estuarinas são locais onde existe uma grande exploração de moluscos bivalves (ARAÚJO, 2001), em Pernambuco, principalmente no litoral Norte a $A$. brasiliana é uma espécie bastante explorada pelo segmento artesanal (LAVANDER,2009). Além disso, a $A$. brasiliana é uma espécie com uma boa aceitação para alimentação e de fácil localização e captura explorada tanto para consumo próprio quanto para comercialização no mercado local (PEZZUTO; ECHTERNACHT, 1999).

Em geral o crescimento de bivalves varia de acordo com a localização geográfica, sendo estimulado pelo maior aporte de alimento e aumento da temperatura, e retardado pela salinidade e baixas temperaturas (ARRIECHE; PRIETO, 2006).

\section{A Qualidade de Moluscos Bivalvos para Comercialização}

De maneira em geral os bivalvos são alimentos muito nutritivos, pois são ricos em proteínas, gorduras (AGpoliinsaturadas - PUFAs) benéficas a saúde do homem, vitaminas e minerais, mas devido a forma como eles se alimentam, são filtradores, filtram as partículas em suspensão na água, e podem eventualmente atuar como um veículo de transmissão de vários agentes causadores de doenças (OGAWA, 1999).

Os agentes que podem ser veiculados são de natureza biológica (bactérias, vírus, parasitas e toxinas de moluscos) e química (metais pesados, resíduos de pesticidas e, mais raramente, antibióticos, quando se trata de cultivo/criação) (DAME, 1996, MORAES, 2000). Assim, a concentração desses elementos presentes na água e nos tecidos desses organismos, reflete as condições ambientais em que vivem, podendo seu consumo trazer sérios danos ao organismo humano, representando um risco à saúde pública, uma vez que alguns moluscos chegam a filtrar até 100 litros de água por dia (DAME, 1996).

A qualidade do pescado, nesse caso dos bivalvos que serão comercializados, está relacionada à qualidade da água de extração ou de cultivo. E para que eles possam ser usados na alimentação humana, seja na forma in natura ou processada, esses organismos devem ser processados com os devidos cuidados nas etapas pós-colheita para assegurar a qualidade do produto.

De modo geral, a qualidade do pescado está sempre associada ao grau de frescor da matéria prima in natura no momento da comercialização. Em relação aos bivalvos, tanto na Europa como aqui no Brasil, recomenda-se que no momento da comercialização eles estejam vivos (com as valvas fechadas), o líquido contido dentro da valva (concha) se apresente límpido (água límpida em seu interior), a carne úmida e aderente à concha, e o cheiro pronunciado de algas marinhas.

No entanto, essa matéria prima, que é um produto de origem animal, é muito perecível porque suas vísceras contêm uma grande quantidade de microrganismos e a própria composição química dos seus tecidos (rico em proteínas e extrativos nitrogenados e etc.) propicia o ataque microbiano, deteriorando facilmente se a manipulação pós-captura ou extração não for adequada, principalmente quanto ao pronto resfriamento desse pescado. É necessário remover calor dos moluscos através do uso adequado do frio (gelo e / ou sistemas de refrigeração) para inibir todos os agentes envolvidos com o fenômeno deterioração (enzimas ativas e microrganismos) (VIEIRA, 2003). 
Quando a cadeia do frio é rompida compromete a qualidade do molusco que vai ser comercializado, ou seja, compromete o seu grau de frescor e consequentemente a sua qualidade sanitária (GONÇALVES, 2011). Alguns fatores podem contribuir para essa perda de qualidade, tais como: as alterações provocadas pelas enzimas do seu próprio corpo. Após a captura, a defesa natural do seu organismo deixa de atuar permitindo que enzimas contidas no intestino desses animais levem a sua deterioração (enzimas que degradam proteínas e lipídeos); a multiplicação de microrganismos, principalmente as bactérias patogênicas de importância em alimentos, que após a captura, sob condições favoráveis (temperatura altas durante a manipulação pós extração) podem se multiplicar no alimento e representar um risco a saúde do consumidor após o seu consumo; a quebra da cadeia de frio. O emprego do gelo ou refrigeração atua na inibição dos principais agentes que levam a deterioração do molusco. Mesmo sob temperaturas de refrigeração $\left(8\right.$ a $\left.-1^{\circ} \mathrm{C}\right)$ essas reações são freadas permitindo que o consumidor e as indústrias recebam essa matéria prima com o frescor necessário para o consumo direto ou para o beneficiamento; más condições de manipulação na captura, na descarga, na depuração, no processamento, no transporte, e na comercialização contribuem para a perda de frescor dos bivalves (GONÇALVES, 2011).

Todos os envolvidos na cadeia produtiva são responsáveis pela manutenção da qualidade, do frescor da matéria prima. Inclusive o consumidor, na sua própria casa, é responsável pela manutenção da qualidade do produto até o seu preparo. Pois, sabe-se que $70 \%$ das Doenças Transmitidas por Alimentos (DTA) são devidas a manipulação inadequada, a falta de higiene. Então, medidas de higiene devem ser tomadas desde a captura até a venda ao consumidor, garantindo desta forma, maior durabilidade desta matéria prima, até mesmo para que ela possa ser recebida pelo consumidor e pela indústria com alto grau de frescor. Além de se evitar os problemas causados por Doenças Transmitidas por Alimentos.

\section{Legislação}

Os bivalvos são organismos filtradores e tem sua qualidade diretamente dependente da situação da água no local onde são cultivados ou extraídos. Para que se possa assegurar a qualidade dos bivalvos produzidos é necessário que eles sejam coletados de águas com qualidade bacteriológica. A colheita deverá ser feita de áreas classificadas de acordo com o preconizado na Resolução CONAMA 357 de 17 de março de 2005, como descrito a seguir:

Ambientes de água doce: classe 2 (Capítulo II, seção 1, artigo 4, parágrafo II) - condições de qualidade da água: limite máximo de 1000 coliformes termotolerantes/100 mililitros ( $80 \%$ ou mais de pelo menos 6 amostras/ano).

Ambientes de água salgada: classe 1 (Capítulo II, Seção 2, artigo 5, parágrafo II) - condições de qualidade da água: limite máximo de 43 coliformes termotolerantes/100 mililitros.

Água salobra: Classe 1 (Capítulo II, seção 2, artigo 6, parágrafo II) - condições de qualidade da água: limite máximo de 43 coliformes termotolerantes/100 mililitros.

Devem atender aos limites legais de microrganismos contaminantes e de biotoxinas marinhas, como preconizado na INSTRUÇÃO NORMATIVA INTERMINESTERIAL N ${ }^{\circ}$
7 de 8 de maio de 2012, onde áreas de extração e de cultivo devem realizar o monitoramento da qualidade da água para toxinas produzidas por algas, além de monitorar a carne do bivalvos. Para o monitoramento de microrganismos contaminantes em bivalvos, preconiza-se o controle para Escherichia coli em 100 gramas da parte comestível dos moluscos bivalvos - NMP/100g). E para o monitoramento de biotoxinas marinhas preconiza-se a quantificação de biotoxinas produzidas por microalgas marinhas em 1 quilograma (Kg) por parte comestível dos moluscos bivalves)

Em Santa Catarina, as empresas certificadas pelo Serviço de Inspeção Federal (SIF) realizam o monitoramento da qualidade da água para toxinas produzidas por algas.

Onde $80 \%$ da produção de SC são destinadas ao mercado interestadual (além do mercado local abastecem também grandes mercados, como os do RJ e SP). As empresas certificadas realizam com recursos próprios o monitoramento da qualidade da água e dos moluscos produzidos.

É importante destacar que esses organismos não devem ser coletada de áreas contaminadas, onde ocorra despejo de esgoto doméstico, resíduos industriais e presença de metais pesados (BRASIL, 2001) .

Os limites microbiológicos para comercialização no mercado interno e externo segue os parâmetros descritos na Resolução $\mathrm{n}^{\circ} 12$, de 02 de janeiro de 2001, da Agência Nacional de Vigilância Sanitária -ANVISA (BRASIL, 2001).

Padrões internacionais, como o EUSQAP (The European Union Shellfish Quality Assurance Programme) classifica os moluscos bivalves em três classes para comercialização: A, B e C. Para cada classe é permitido uma quantidade de coliformes termotolerantes por $100 \mathrm{~g}$ de massa visceral e líquido intervalvar. Para a classe A, a tolerância é de < $300 \mathrm{CT} / 100 \mathrm{~g}$, na classe $\mathrm{B}, 90 \%$ das amostras não podem exceder $6.000 \mathrm{CT} / 100 \mathrm{~g}$ e na classe $\mathrm{C}$, não podem exceder a $60.000 \mathrm{CT} / 100 \mathrm{~g}$.

\section{O Consumo de Bivalvos x Riscos à Saúde Pública}

$\mathrm{O}$ processo de intervenção e controle dos agravos à saúde do consumidor tem despertado interesse e se revelado efetivo na diminuição de certos riscos microbianos, como a presença de Salmonella spp, Shigella spp, Escherichia coli O157:H7 e Vibrio cholerae toxigênico, dentre outros (VARNAM; EVANS, 1991).

Sob o ponto de vista microbiológico, a qualidade do vôngole vendido in natura em Itaguaí é duvidosa e a comercialização é realizada as margens da baía de Sepetiba, cujo controle sanitário mostra-se precário, apontando a necessidade de investigação sob o ponto de vista sanitário.

A elevada ocorrência de Escherichia coli é particularmente reportada em infecções gastrentéricas, tanto em indivíduos imuno comprometidos, como naqueles sadios. Dessa forma, a presença desse microrganismo é reconhecida como um indicador de outros patógenos, tanto de natureza bacteriana quanto viral ou parasitária, cujos prejuízos à população são amplamente reconhecidos (BRASIL,2001).

A Legislação preconiza ausência total para Salmonella em qualquer amostra aleatória de $25 \mathrm{~g}$ (BRASIL, 2001). Nos Estados Unidos da América, as salmonelas não tifóides têm sido associadas ao consumo de peixes e crustáceos, Salmonella Paratyphi e S. Enteridis a camarões e moluscos bivalves e $S$. Typhi o principal agente associado com doenças veiculadas por moluscos (FELDHUSEN, 2000). 
A presença de enterococos em amostras de moluscos sugere um alto grau de contaminação na água de cultivo por esgotos. No entanto, na legislação não há limites para esse gênero em amostras de ostras. Segundo Morelli et al. (2003) a presença de Enterococcus faecalis foi observada em $70 \%$ de ostras comercializadas em dois estabelecimentos na Praia do Futuro, enquanto Silva et al. (2004) confirmaram o mesmo microrganismo em $68 \%$ dos isolados de ostras, coletadas no estuário do Rio Cocó. O grupo dos coliformes quando comparado aos enterococos são mais fáceis de serem isolados e identificados, além de estarem mais relacionados a infecções intestinais, embora os enterococos sejam mais resistentes às condições ambientais adversas, ao congelamento e sobreviva maior tempo em alimentos congelados (JAY, 1991).

Outro grupo importante relacionado a surtos alimentares são os víbrios. Estes microrganismos fazem parte da microbiota natural de ambientes marinhos e estuarinos. A quantificação de Vibrio e coliformes em amostras de água e ostras Crassostrea rhizophorae, coletadas no estuário do Rio Jaguaribe, município de Fortim - CE, foi maior nas amostras de ostras do que na água, confirmando o potencial bioacumulador destes organismos (VIEIRA et al., 2007).

A água é o ambiente natural de V.parahaemolyticus e por este microrganismo está associado a diversos surtos alimentares, sua presença traz diversos riscos aos consumidores. Pereira et al. (2004) analisando amostras de ostras provenientes de 15 restaurantes no Rio de Janeiro, revelaram a elevada incidência de $V$. parahaemolyticus $(86 \%)$ nas ostras comercializadas nesses estabelecimentos.

SOUSA et al. (2004) isolaram Vibrio parahaemolyticus e $V$. cholerae, em 12amostras de ostras, coletadas no estuário do Rio Cocó, Ceará, observando a presença de $V$. choleraenão 01 e não $0139 \mathrm{e}$ V. parahaemolyticus em 33 e $8 \%$ das amostras, respectivamente.

Diferentes organismos aquáticos, como os mariscos, ostras, vôngole e etc. têm sido considerados como habitats potenciais de $V$. Cholerae $\mathrm{O} 1$ no meio aquático, onde esta interação parece estar associada à capacidade desses víbrios produzirem quitinase e usarem a quitina da carapaça desses organismos como fonte denutrientes (GASPARI et al., 2006).

Outro microrganismo relevante é o gênero Aeromonas que de um modo geral são os contaminantes mais comuns encontrados em peixes e produtos marinhos, uma vez que este gênero é primariamente autóctone de ambientes aquáticos (HÃNNINEN et al., 1997). Nos rios, elas fazem parte da microbiota normal podendo até se multiplicar em condições ambientais adequadas (MORES, 1994). A presença de Aeromonas spp. foi observadaem 67\% das amostras de ostras estudadas por Evangelista-Barreto et al. (2006).

Com relação à presença dos vírus, Barardi et al. (2001) citam que a ocorrência desses microrganismos de cultivo como o vírus da hepatite A (eliminado nas fezes de pessoas infectadas)e os causadores de diarréias severas (rotavírus, astrovírus, vírus Norwalk dentre outros) podem ser encontrados tanto emáguas liberadas para o consumo humano quanto em moluscos. Mais resistentes ao tratamento de esgotos, esses microrganismos sobrevivem mais tempo do que as bactérias em ambientes naturais, tendo outro padrão a distribuição nas diversas épocas do ano. VIEIRA (1999)relatou o isolamento do vírus Small Round Structured Viruses - SRSV causador de gastroenterite, e naturalmente presente e mostras contaminadas.
Outro fato importante para as autoridades sanitárias se refere à resistência antimicrobiana bacteriana que tem aumentado nos últimos anos em virtude da prescrição excessiva de antibióticos por parte de médicos, o uso indiscriminado pelo público e o emprego dessas drogas nos cultivos intensivos de animais (HARAKEH et al., 2006). O uso de antibióticos nas rações, visando efeito profilático no tratamento de infecções animais como promotor de crescimento tem contribuído para a perpetuação de estirpes resistentes e patogênicas (PINTO,2000).

\section{Beneficiamento dos bivalves:}

A comercialização dos bivalvos in natura é muito praticada. Porém, o armazenamento desse produto é difícil porque as conchas ocupam muito espaço. Quando beneficiada desde a entrada do produto na planta processadora, até o preparo para a sua expedição, as empresas adotam uma série de procedimentos de boas práticas de fabricação, todos normatizados pelo SIF, de forma a garantir o fornecimento de alimento seguro aos seus consumidores.

Figura 1. Fluxograma do processamento de ostras/mexilhões congelados em meia concha

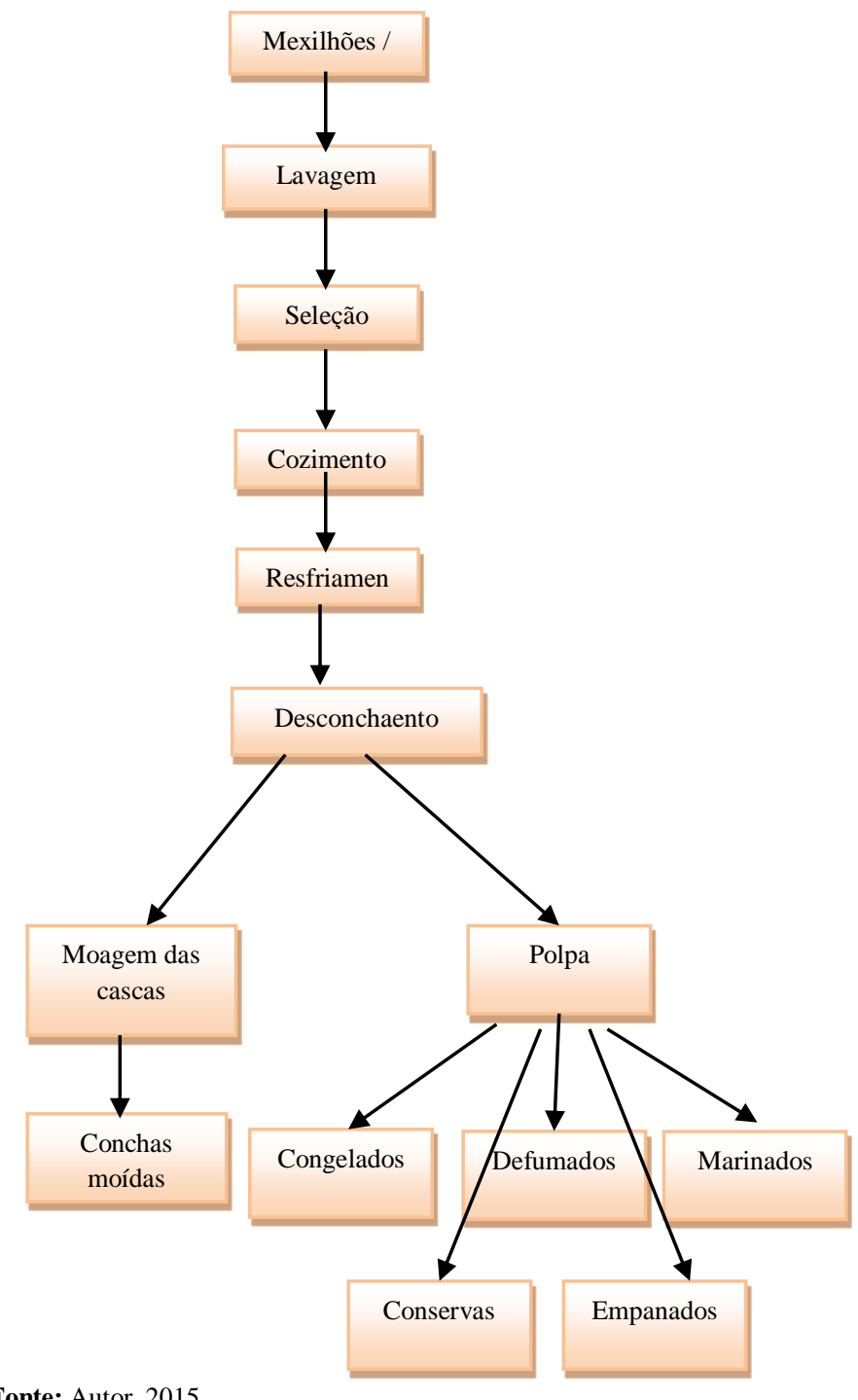

Fonte: Autor, 2015

Fluxograma: Processo tecnológico de moluscos bivalvos 
Para facilitar a compreensão do processo tecnológico de bivalvos, o fluxograma descrito abaixo evidencia as etapas operacionais para o processamento de mexilhões e/ou ostras congeladas em meia concha.

\section{Descrição do Fluxograma:}

Em relação aos operários (manipuladores de alimentos) é importante ressaltar que todos os envolvidos com a manipulação das ostras e / ou mexilhões e/ou vôngoles devem usar uniforme limpos e claros, ter higiene pessoal e realizar exame médico anual e possuir carteira de saúde. Devem receber treinamento sobre manipulação de alimentos e BPFs .

Recepção: proceder ao controle da qualidade da matériaprima; Os moluscos que forem beneficiados devem apresentar grau de frescor, pois o frescor diminui com o passar do tempo dependendo das condições de armazenamento a que são submetidos; Pesar os moluscos; descartar todos os bivalvos cuja qualidade esteja comprometida (mortos, danificados, abertos). Se a linha de processamento estiver ocupada, os bivalvos deverão ficar em uma câmara de estocagem ou em tanques de PVC contendo gelo em escamas para o resfriamento.

Lavagem: O objetivo é limpar as valvas sem que haja danos físicos as mesmas, por isso, a lavagem é efetuada através de lavadores a jato. Os tambores rotativos (envolvem choques) não são usados porque poderiam promover a quebra indesejável.

A qualidade da água de lavagem afeta a qualidade do produto final. Alguns fatores associados à água interferem na qualidade dos produtos, como: temperatura, dureza, conteúdo de minerais, pH e salinidade. Então, a água deve ser refrigerada para que as proteínas possam manter suas propriedades funcionais. A temperatura recomendada é de $10^{\circ} \mathrm{C}$ ou menos. A água ideal para a lavagem deverá apresentar teores mínimos de $\mathrm{Ca} / \mathrm{Mg} / \mathrm{Fe} / \mathrm{Mn}$, pois a água dura causa deterioração da qualidade da textura e cor durante a armazenagem sob congelamento, sendo $\mathrm{Ca}$ e $\mathrm{Mg}$ responsáveis por alterações de textura e $\mathrm{Fe}$ e $\mathrm{Mn}$ responsáveis por variações na cor. $\mathrm{O}$ pH deve ser mantido entre 6,5 e 7,0 para garantir capacidade máxima de retenção de água

Desconchamento: as conchas devem ser lavadas logo após a colheita para remoção das sujidades presentes na sua superfície. A água utilizada para a lavagem deve ter qualidade (pode usar a do cultivo ou de outra fonte);

Todos os equipamentos e utensílios utilizados (mesas, bancadas, caixas PVC, facas e etc.) devem estar limpos. Sempre que necessário fazer a limpeza e desinfecção durante a operação.

Nas mesas de desconchamento, cada unidade de matéria-prima (cada indivíduo ou concha) terá uma de suas conchas removida manualmente. Após a remoção das conchas, as polpas devem ser lavadas em água limpa e corrente, sem muita agitação, para evitar que haja perda de sabor.

OBS1.: Moluscos vivos, as conchas estão fortemente unidas (fechadas), ou se fecham quando tocadas. Se permanecerem abertas é porque os moluscos estão morrendo ou já estão mortos. Quando cozidos, entretanto, estas se abrem, facilitando a remoção da polpa.

$\mathrm{OBS}_{2} .:$ A carne também poderá ser removida após o cozimento em vapor por 4 minutos ou em água quente por 6 minutos. Os produtores utilizam mais água quente porque desta forma a carne perde menos volume. Tempos de cozimentos maiores são usados quando se quer cozinhar a carne. A carne deve ser removida da casca, rapidamente lavada em água corrente limpa para que não ocorra perda de sabor, e o produto se torna menos atrativo.

$\mathrm{OBS}_{3}$.: quando o produto for apresentado em meia concha, deve-se proceder uma segunda lavagem em água corrente logo após o semi-desconchamento para que resíduos de cascas sejam removidos. Ter cuidado para não danificar a polpa.

Congelamento: o mexilhão pode ser congelado com casca por períodos longos, no entanto, economicamente não é viável pelo volume ocupado. A carne após cozida e limpa pode ser embalada em caixas de papelão (as mais usadas), em sacos plásticos, ou até mesmo bandejas envoltas em filme retrátil que permite a evacuação do ar, o que aumenta o tempo de conservação do produto. $\mathrm{O}$ produto também pode ser congelado sem embalagem para receber o glaseamento e ser embalado a seguir.

O mexilhão é congelado a uma temperatura máxima de $-27^{\circ} \mathrm{C}$, por um período de 50 minutos, e estocado à temperatura de $-18^{\circ} \mathrm{C}$. As ostras são depositadas em cestos de arame que comportam 12 unidades cada, e logo depois são colocadas sobre as prateleiras de carrinhos que são diretamente enviados à câmara de congelamento. Desta forma, o produto será submetido ao processo de congelamento ainda sem ser acondicionado na embalagem final, o que torna o processo de congelamento mais demorado. A temperatura de congelamento deverá ser da ordem de $-30^{\circ} \mathrm{C}$

OBS.: Glaseamento: uma forma de preservar a qualidade do pescado evitando a dessecação e a rancificação, pode ser feita da seguinte maneira: glasear com água pura; com soluções aquosas de antioxidantes, formando uma película protetora de gelo na superfície do pescado.

A comercialização da produção que é realizada pelos produtores não certificados pelos serviços de inspeção, em alguns casos, sem os devidos cuidados higiênico-sanitários necessários para a venda para consumo humano direto pode acarretar em surtos de doenças alimentares vinculadas a esses moluscos, contribuindo para um marketing negativo da atividade como um todo.

A prática de higiene é necessária desde a recepção da matéria prima até a sua expedição. No controle da qualidade da água utilizada, na eliminação dos riscos de contaminação em qualquer das etapas de processamento (na colheita e pós colheita e no beneficiamento); e da conscientização dos manipuladores, do controle de insetos e roedores.

Prevenir é a melhor recomendação para garantir as perdas devidas à deterioração, não importa em que elo da cadeia produtiva (no cultivo, durante a despesca, no transporte, na indústria, ou na casa do consumidor).

OBS.: Certificação Sanitária

Em nível de Brasil dois problemas podem ser identificados:

- Não existe certificação sanitária das áreas de cultivo para bivalvos, nem mesmo mecanismos legais para tal certificação. Em países como a União Européia, EUA e Chile esses critérios são bem regulamentados. A fim de evitar danos à saúde pública são conhecidas três regras básicas e simples quanto à manipulação de mexilhões, internacionalmente adotadas: transportá-los rapidamente, mantê-los limpos e refrigerados, e cozinhá-los em temperatura adequada. 
Atualmente, a garantia da qualidade dos moluscos bivalves é dada pela correta manipulação ou pela depuração do produto feitas em estabelecimentos apropriados. Sendo sua certificação sanitária é dada pelo Ministério da Agricultura (SIF - Serviço de Inspeção Federal).

\section{Referências}

AVELAR, J. C. L. Manual de Mitilicultura. 1.ed. Brasília: Ministério do Meio Ambiente, 1998. 164 p.

BATISTA, V.S.; BARBOSA, W.B. Descarte de peixes na pesca comercial em Tefé, médio Solimões, Amazônia Central. ActaScientiarum Biological Sciences, v.30, n.1, p.97105, 2008.

BELOT, M.; JAMES, J. Healthy school meals and educational outcomes.Journalof Health Economics, v. 30, p.489-504, 2011.

BEZERRA, J.A.B. Alimentação e escola: significados e implicações curriculares da merenda escolar. Revista Brasileira de Educação, v. 14, n. 40, p.103-115, 2009.

BISPO, E. S. Aproveitamento industrial de marisco na produção de lingüiça. Revista Ciência e Tecnologia de Alimentos, Campinas, v. 24, n.4, p.664-668, 2004a.

BISPO, E. S. SANTANA, L.R.R.; CARVALHO, R.D.S. Processamento, estabilidade e aceitabilidade de marinado de vôngole (Anomalocardia brasiliana). Revista Ciência e Tecnologia de Alimentos, v. 24, n. 3, p. 353-356, 2004b.

BOEHS, G.; ABSHER, T. M.; CRUZ-KALED, A. C. Ecologia populacional de Anomalocardia brasiliana (GMELIN, 1791) (Bivalvia, Veneridae) na baía de Paranaguá, Paraná, Brasil. Boletim do Instituto de Pesca, v. 34, n. 2, p. 259-270, 2008.

BOEHS, G.; MAGALHÃES, A. R. M. Simbiontes associados com Anomalocardia brasiliana (Gmelin) (Mollusca, Bivalvia, Veneridae) na Ilha de Santa Catarina e região continental adjacente, Santa Catarina, Brasil. Revista Brasileira de Zoologia, v. 21, n. 4, p. 865-869, 2004.

BOFFI, A. V. Moluscos brasileiros de interesse médico e econômico. São Paulo: Hucitec, 1979.

BRASIL. Agência Nacional de Vigilância SanitáriaANVISA. Resolução $\mathrm{n}^{\circ} 12$, de 02 de janeiro de 2001. Regulamento técnico sobre os padrões microbiológicos para alimentos. Disponível em: <http://portal.anvisa.gov.br/wps/wcm/connect/a47bab804745 8b909541d53fbc4c6735/RDC_12_2001.pdf?MOD=AJPERE S>Acesso em: 19 Out. 2014.

BRASIL. Medida Provisória n ${ }^{\circ}$ 2.178-36, de 24 de agosto de 2001. Dispõe sobre o repasse de recursos financeiros do Programa Nacional de Alimentação Escolar, institui o Programa Dinheiro Direto na Escola, altera a Lei $n^{\circ}$ 9.533, de 10 de dezembro de 1997, que dispõe sobre programa de garantia de renda mínima, institui programas de apoio da União às ações dos Estados e Municípios, voltadas para o atendimento educacional, e dá outras providências.
Disponível

em:

<http://www.camara.gov.br/proposicoesWeb/prop_mostrarint egra;jsessionid=204EFC595C6C5466DD221C4383272616.n ode2?codteor $=682485 \&$ filename $=$ LegislacaoCitada+PL+5837/2009> Acesso em: 04 Ago. 2014.

BRASIL. Ministério da Agricultura, Pecuária e Abastecimento. Instrução Normativa $\mathrm{n}^{\circ}$ 62, de 26 de agosto de 2003. Oficializa os métodos analíticos oficiais para análises microbiológicas para o controle de produtos de origem animal e água. Disponível em: <http://www.hidrolabor.com.br/IN62.pdf> Acesso em: 19 Out. 2014.

BRASIL. Ministério da Agricultura, Pecuária e Abastecimento. Secretaria Nacional de Defesa Agropecuária. Laboratório Nacional de Referencia Animal (LANARA). Métodos analíticos oficiais para o controle de produtos de origem animal e seus ingredientes. II. Métodos Físicos Químicos. Brasília, 1981. 123p.

BRASIL. Ministério da Educação. Resolução CD/FNDE $n^{\circ}$ 26, de 17 de junho de 2013.

BRASIL. Ministério da Pesca e Aquicultura. Boletim Estatístico da Pesca e Aquicultura. 2012. Disponível em:<http://www.mpa.gov.br/images/Docs/Informacoes_e_Est atisticas/Boletim\%20Estat\%C3\%ADstico\%20MPA\%202010. pdf> Acesso em: 11 Jul.2013.

BRASIL. Ministério da Pesca e Aquicultura. Boletim Estatístico da Pesca e Aquicultura. 2013a. Disponível em: <http://www.mpa.gov.br/images/Docs/Informacoes_e_Estatis ticas/Boletim\%20MPA\%202011FINAL.pdf > Acesso em: 14 Set.2013.

BRASIL. Secretaria Especial de Aquicultura e Pesca. Plano de Desenvolvimento Sustentável da Aquicultura e Pesca: Mais Pesca e Aquicultura. [s.d.]. Disponível em: $<$ http://www4.planalto.gov.br/consea/eventos/eventosanteriores/seminario-semana mundial-da-alimentacao-osdesfios-para-a-seguranca-alimentar-e-nutricional-e-as respostas-do-governo-brasileiro/palno-de-desenvolvimentosustentavel-da-aquicultura-e-pesca> Acesso em: 04 Ago.2013.

CARVALHO, S. M. S. Possibilidades e limitações do desenvolvimento sustentável do turismo no município de Cajueiro da Praia (PI). 2010. 164 f. Dissertação (Mestrado em Desenvolvimento e Meio Ambiente) Universidade Federal do Piauí, Teresina, 2010.

CATTANI, A.P.; SANTOS, L.O.; SPACH, H.L.; BUDEL, B.R.; GONDIM GUANAIS, J.H.D. Avaliação da ictiofauna da fauna acompanhante da pesca do camarão sete-barbas do município de Pontal do Paraná, Litoral do Paraná, Brasil. Boletim do Instituto de Pesca, v.32, n.2, p.247-260, 2011.

CENTENARIO, G.S.; FEDDERN, V.; BONOW, E.T.; SALAS-MELLADO, M. Enriquecimento de pão com proteínas de pescado. Ciência e Tecnologia de Alimentos, v.27, n.3, p. 663-668, 2007. 
CHAVES, L.G. Políticas de Alimentação Escolar. 2006. Disponível em:

http://portal.mec.gov.br/seb/arquivos/pdf/profunc/12_pol_ali ment_escol.pdf > Acesso em: 04 Ago. 2013.

CONSELHO FEDERAL DE NUTRICIONISTAS. Resolução CFN $n^{\circ} 358$, de 18 de maio de 2005. Dispõe sobre as atribuições do Nutricionista no âmbito do Programa de Alimentação Escolar (PAE) e dá outras providências. Disponível

<http://www.cfn.org.br/novosite/pdf/res/2005/res358.pdf > Acesso em: 04 Ago. 2013.

COSTA, A. S. Turismo de desenvolvimento local sustentável em Barra Grande. 2006. 106 f. Dissertação. (Mestrado em Desenvolvimento e Meio Ambiente) Universidade Federal do Piauí, Teresina, 2006.

COSTA, F. A. P. da. Cronologia histórica do estado do Piauí. Rio de Janeiro: Artenova, 1974.

COSTA,M.R.;

SANTOS,A.B.L.;

ALBIERI,R.J.;

NEVES,L.M.; ARAUJO,F.G

DistributionandsizeofthemojarraDiapterusrhombeus(cuvier)

(actinopterygii, gerreidae) in a southeasternbrazilianbay. BrazilianJournalofOceanography, v.60, n.2, p.199-207, 2012.

COSTA-NETO, E. M. Os moluscos na zooterapia: medicina tradicional e importância clínico-farmacológica. Revista Biotemas, v.19, n.3, p. 71-78, 2006.

CUNHA, D.T.; FIOROTTI, R.M.; BALDASSO, J.G.; SOUSA, M.; FONTANEZI, N.M.; CAIVANO, S.; STEDEFELDT, E.; ROSSO, V.V.; CAMARGO, M.C. Improvement of food safety in school meal service during a long-term intervention period: a strategy based on the knowledge, attitude and practice triad. Food Control, v.34, p.662-667, 2013.

DAVIES, R.W.D.; CRIPPS, S.J.; NICKSON, A.; PORTER, G. Defining and estimating global marine fisheries bycath.Marine Policy, v.33, p.661-672, 2009.

DIAS, T. L. P.; ROSA, R. S.; DAMASCENO, L. C. P. Aspectos socioeconômicos, percepção ambiental e perspectivas das mulheres marisqueiras da Reserva de Desenvolvimento Sustentável Ponta do Tubarão (Rio Grande do Norte, Brasil). Gaia Scientia, v. 1, n. 1, p. 25-35, 2007.

DIAS-NETO, J.; DORNELLES, L. D. C. Diagnóstico da pesca marítima do Brasil. Brasília, IBAMA, coleção Meio Ambiente, série Estudos Pesca, 20. Brasília, 1996.

DIEGUES, A. C. (org.). Saberes tradicionais e biodiversidade no Brasil. Brasília: Ministério do Meio Ambiente, São Paulo: USP, 2000.

DIEGUES, A. C. A pesca construindo sociedades. São Paulo: Núcleo de Apoio à Pesquisa sobre Populações Humanas e Áreas Úmidas Brasileiras/USP, 2004.

DIEGUES, A. C. Comunidades litorâneas e os manguezais do Brasil. In: DIEGUES, A. C. S., ARRUDA, R. S. V. (Orgs.).
Saberes tradicionais e biodiversidade no Brasil. Brasília: Ministério do Meio Ambiente, 2001.

Dispõe sobre o atendimento da alimentação escolar aos alunos da educação básica no âmbito do Programa Nacional de Alimentação Escolar - PNAE. Disponível em< http://www.fnde.gov.br/fnde/legislacao/resolucoes/item/4620resolu\%C3\% A7\% $3 \%$ A3o-cd-fnde-n\%C2\%BA-26,-de-17de-junho-de-2013> Acesso em: 17 Fev.2014.

EL-DEIR, S. G. Estudo da mariscagem de Anomalocardia brasiliana (Mollusca: Bivalvia) nos bancos de coroa do Aviao, Ramalho e Mangue Seco (Igarassu-Pernambuco, Brasil). 2009. 120 f. Tese. (Doutorado em Oceanografia) Universidade Federal de Pernambuco, Recife, 2009.

FLOAGRO. Consultoria e planejamento agroflorestal e ambiental. Relatório de impacto ambiental - RIMA: projeto de criação de camarão marinho, fazenda Fartura, Cajueiro da Praia, PI. Piauí, 2003.

FOOD AND AGRICULTURE ORGANIZATION - FAO. 2012. The State of World Fisheries and Aquaculture. Disponível em: < http://www.fao.org/docrep/016/i2727e/i2727e.pdf> Acesso em: 11 Jul. 2013.

FOOD AND AGRICULTURE ORGANIZATION - FAO. 2013a. Reduction of bycatch and discards. 2013b. Disponível em: < http://www.fao.org/fishery/topic/14832/en> Acesso em: 11 Out. 2013.

FOOD AND AGRICULTURE ORGANIZATION FAO.2013b. Fisheries and Aquaculture Department.Composition of fish.Disponível em: < http://www.fao.org/fishery/topic/12318/en> Acesso em: 08 Out. 2013.

FOOD AND AGRICULTURE ORGANIZATION- FAO. 2007. The State of World Fisheries and Aquaculture. Disponível em: <ftp://ftp.fao.org/docrep/fao/009/a0699e/a0699e.pdf> Acesso em: 26 Out. 2013.

FUNDAÇÃO INSTITUTO DE PESCA DO ESTADO DO RIO DE JANEIRO - FIPERJ. Pesca Marinha. A Pesca no Estado do Rio de Janeiro. [s.d.]. Disponível em: $<$ http://www.fiperj.rj.gov.br/index.php/main/pesca> Acesso em: 11 Jul.2013.

FUNDAÇÃO INSTITUTO DE PESCA DO ESTADO DO RIO DE JANEIRO - FIPERJ. Relatório 2011. Fundação Instituto de Pesca do Estado do Rio de Janeiro. Disponívelem:

<http://www.fiperj.rj.gov.br/fiperj_imagens/arquivos/revistar elatorios2011.pdf> Acesso em: 11 Jul.2013.

FUNDO NACIONAL DE DESENVOLVIMENTO DA EDUCAÇÃO - FNDE - Resolução no 32, de 10 de agosto de 2006a. Estabelece as normas para a execução do PNAE. Disponível

em:<http://www.fnde.gov.br/fnde/legislacao/resolucoes/item/ 3106resolu\%C3\% A7\%C3\%A3o-cd-fnde-n\%C2\%BA-32-de10-de-agosto-de-2006> Acesso em: 04 Ago.2013. 
FUNDO NACIONAL DE DESENVOLVIMENTO DA EDUCAÇÃO-FNDE- Resolução no 33, de 24 de agosto de 2006b. Altera o exposto no artigo 9 da Resolução no 32, de 10 de agosto de 2006. Disponível em: <http://www.fnde.gov.br/fnde/legislacao/resolucoes/item/310 7-resolu\%C3\%A7\%C3\%A3o-cd-fnde-n\%C2\%BA-33-de-24de-agosto-de-2006> Acesso em: 04 Ago.2013.

GODOY, L.C.; FRANCO, M.L.R.S.; FRANCO, N.P.; SILVA,A.F.; $\quad$ ASSIS,M.F.; $\quad$ SOUZA,N.E.; MATSUSHITA,M.; VISENTAINER, J.V. Análise sensorial de caldos e canjas elaborados com farinha de carcaças de peixe defumadas: aplicação na merenda escolar, Ciência e Tecnologia de Alimentos, v.30, Suppl.1, p.86-89, 2010.

GONÇALVES, A.A. Aspectos Gerais do Pescado. In: GONÇALVES, A.A. Tecnologia do Pescado: Ciência, Tecnologia, Inovação e Legislação. São Paulo: Editora Atheneu, 2011. p.02-09.

GROTTA, M.; LUNETTA, J. E. Ciclo sexual de Anomalocardia brasiliana (Gmelin, 1791) do litoral do Estado da Paraíba. Revista Nordestina de Biologia, v. 3, n.1, p. 5-55, 1980.

GUEDES, A.P.P. Hábitos Alimentares e Organização Trófica da Comunidade de Peixes da Baía de Sepetiba, Rio de Janeiro, Brasil. 2010. 134f. Tese (Doutorado em Biologia Animal) - Instituto de Biologia, Universidade Federal Rural do Rio de Janeiro, Seropédica.

HART, F.L.; FISHER, H.J. Analisismodern de los alimentos. Zaragoza: Acribia, 1971.

HAVERROTH, M. 1997. Etnobotânica: uma revisão teórica. Antropologia em primeira mão, v. 20, p. 1-56, 1997.

HE,C.; BREITING,S.; PEREZ-CUETO,F.J.A. Effect of organic school meals to promote healthy diet in 11-13 year old children. Appetite, v.59, p. 866-876, 2012.

HIGUCHI, L. H.; DALLAGNOL, J. M.; BOSCOLO, W. R.; FEIDEN, A.; SIMÕES, M.R.; MALUF, M. L. F.; FARIÑA, L. O. Desenvolvimento de almôndega e quibe de pescado, como alternativa para merenda escolar em Itaipulândia, PR. Higiene Alimentar, v.26, n.204/205, p.110-115, 2012.

IBAMA. Instituto Brasileiro do Meio Ambiente e dos Recursos Naturais Renováveis. Documento Legal. Disponível em: <www.ibama.gov.br/siucweb/mostraDocLegal.php>. Acesso em: 13 dez. 2010.

INSTITUTO ADOLFO LUTZ- IAL. Métodos físicoquímicos para análise de alimentos. Edição IV. I Edição Digital. São Paulo. Capítulo XVIII. Pescado e Derivados. 2008a.

INSTITUTO ADOLFO LUTZ- IAL. Métodos físicoquímicos para análise de alimentos. Edição IV. I Edição Digital. São Paulo. Capítulo VI. Análise Sensorial. 2008b.

INSTITUTO BRASILEIRO DE GEOGRAFIA E ESTATÍSTICA - IBGE. Pesquisa de Orçamentos Familiares
2008-2009: Aquisição Alimentar Domiciliar Per Capita. Rio de Janeiro: IBGE, 2010a.

INSTITUTO BRASILEIRO DE GEOGRAFIA E ESTATÍSTICA - IBGE. Pesquisa de Orçamentos Familiares 2008-2009: Despesas, Rendimentos e Condições de Vida. Rio de Janeiro: IBGE, 2010b.

INSTITUTO ESTADUAL DO AMBIENTE -INEA- [s.d.]. Baía de Sepetiba. Disponível em: <http://www.inea.rj.gov.br/fma/baia-sepetiba.asp> Acesso em: 11 Jul. 2013.

JAY, J.M. Modern food microbiology. 5. ed. New York: Chapman e Hall, 1996.

JONES, C. G.; LAWTON J. H.; SHACHAK M. Organisms as ecosystem engineers.Oikos, v. 69, p. 373-386, 1994.

JONES, C. G.; LAWTON J. H.; SHACHAK M. Positive and negative effects of organisms as physical ecosystem engineers.Ecology, v. 78, p. 1946-1957, 1997.

LARSEN, R.; EILERTSEN,K.E.; ELVEVOLL,E.O. Health benefits of marine foods and ingredients. BiotechnologyAdvances, v.29, p.508-518, 2011.

LEARDINI pescados faz parceria com a Disney. EcoFinanças. 02 Out. 2012. Disponível em: <http://www.ecofinancas.com/noticias/leardini-pescados-fazparceria-disney> Acesso em: 08 Mar. 2014.

LEOS-URBEL,J.; SCHWARTZ,A.E.; WEINSTEIN,M.; CORCORAN,S. Not just for poor kids: the impact of universal free school breakfast on meal participation and student outcomes. EconomicsofEducationReview, v.36, p.88107, 2013.

LIRA, G. M. Perfil de ácidos graxos, composição centesimal e vaor calórico de moluscos crus e cozidos com leite de coco na cidade de Maceió-AL. Revista Brasileira de Ciências Farmacêuticas. v. 40, n. 4, 2004.

MARCHINI, J. S.; VITALI, L. H.; JORDÃO J, A.; RODRIGUES, M. M. P.; DUTRA DE OLIVEIRA, J. E. Determinação de macronutrientes em alimentos normalmente consumidos pela população brasileira. Revista do Instituto Adolfo Lutz, v. 53, p. 11-16, 1993.

MARINEBIO. Bonefishes, Albulavulpes. [s.d.]. Disponível em: <http://marinebio.org/species.asp?id=393> Acesso em: 14 Set. 2013.

MARTINS, V. S.; SOUTO, F. J. B. Uma análise biométrica de bivalves coletados por marisqueiras no manguezal de Acupe, Santo Amaro, Bahia: uma abordagem etnoconcervacionista. Sitientibus Série Biológicas, v. 6, p. 98 $105,2006$.

MAVIGNIER, D. S.; MOREIRA, A. M. Conhecendo História e Geografia do Piauí. Parnaíba, PI: Parque da Gráfica Ferraz, 2007. 
MCLACHLAN, A. Sandy beachecology: a review. In: MCLACHLAN, A.; ERASMUS, T. (eds.), Sandy beaches as ecosystems. The Hague: W. Junk, p. 321-380, 1983.

MELLO, S.C.R.P.; FREITAS, M.O.; SÃO CLEMENTE, S.C.; FRANCO, R.M.; NOGUEIRA, E.B.; FREITAS, D.D.G.C. Development and bacteriological, chemical and sensory characterization of fishburgers made of tilapia minced meat and surimi. Arquivo Brasileiro de Medicina Veterinária e Zootecnia, v.64, n.5, p.1389-1397, 2012.

\section{MITTERER-DALTOÉ,M.L.;}

LATORRES,J.M.; CARBONERA, N.; PASTOUS-MADUREIRA， L.S.; QUEIROZ,M.I. Potencial de inserção de empanados de pescado na merenda escolar mediante determinantes individuais. Ciência Rural, v.42, n.11, p.2092-2098, 2012.

MOREIRA, I. C. N. Impactos do extrativismo de Anomalocardia brasiliana (Gmelin, 1791) nos estuáios dos rios Paciência e Cururuca, São Luis, Maranhão: uma visão etnoconservacionista. 2007. 60 f. Dissertação (Mestrado em Biodiversidade e Conservação) Universidade Federal do Maranhão, São Luis, 2007.

MOTA, C.H.; MASTRONI, S.S.B.S.; MASTROENI, M.F. Consumo da refeição escolar na rede pública municipal de ensino. Revista Brasileira de Estudos Pedagógicos, v. 94, n. 236, p.168-184, 2013.

MOUËZA, M.; GROS, O.; FRENKIEL, L. Embryonic, larval and postlarval development of the tropical clam, Anomalocardiabrasiliana (Bivalvia, Veneridae).Journal of Molluscan Studies, p. 73-88, 1999.

MUSTAFA, F.A.; MEDEIROS, D.M. Proximate composition, mineral content and fatty acids of catfish (Ictalaruspuntactus, Rafinesque) for different seasons and cookin methods. JournalofFood Science, v. 3, p. 585-589, 1985.

NARCHI, W. Ciclo anual da gametogênese de Anomalocardia brasiliana (Gmelin, 1791) (MolluscaBivalvia). Bolm. Zool, v. 1, p. 331-350, 1976.

NEIVA, C.R.P.; MACHADO, T.M.; TOMITA, R.Y.; FURLAN, E.F.; LEMOS NETO, M.J.; BASTOS, D.H.M.Fish crackers development from minced fish and starch: an innovative approach to a traditional product. Ciência e Tecnologia de Alimentos, v. 31, n.4, p. 973-979, 2011.

NEIVA,C.R.P.; GONÇALVES, A.A. Carne Mecanicamente Separada (CMS) de Pescado e Surimi. In: GONÇALVES, A.A. Tecnologia do Pescado: Ciência, Tecnologia, Inovação e Legislação. São Paulo: Editora Atheneu, 2011. p.197-207.

NETO, A.D.L.; GONÇALVES, A.A. Formatados e Reestruturados (Hambúrguer, Nuggets etc.) In: GONÇALVES, A.A. Tecnologia do Pescado: Ciência, Tecnologia, Inovação e Legislação. São Paulo: Editora Atheneu, 2011. p.235-245.

NIBBAKEN, J. W. Marine Biology: An Ecological Approach. 5 ed. Benjamin Cummings: San Francisco. 2001.
NISHIDA, A. K. A.; NORDI, N.; ALVES, R. R. D. N. Abordagem etnoecológica da coleta de moluscos no litoral Paraibano. Tropical Oceanography, v. 32, n.1, p. 53-68, 2004.

NISHIDA, A. K. A.; NORDI, N.; ALVES, R. R. D. N. Aspectos socioeconômicos dos catadores de moluscos do litoral paraibano, Nordeste do Brasil. Revista de Biologia e Ciências da Terra. v. 8, n. 1, p. 207-215, 2008.

NOBLE, C.; CORNEY, M.; EVES, A.; KIPPS, M.; LUMBERS, M. Food choice and school meals: primary schoolchildren's perceptions of the healthiness of foods and the nutritional implications of food choices. Hospitality Management, v.19, p.413-432, 2000.

OGAWA, M.; MAIA, E. L. Manual de pesca: ciência e tecnologia do pescado. São Paulo: Livraria Varela, 1999.

OLIVEIRA, I. B. Estudo da estrutura populacional da Anomalocardia brasiliana (GMELIN, 1791) na praia do Mangue Seco, litoral Norte de Pernambuco, Brasil. 2010. 76 f. Dissertação (Mestrado em Recursos Pesqueiros e Aquicultura). Universidade Federal Rural de Pernambuco, 2010 .

PAIVA. A. C. G.; COELhO, P. A.; TORRES, M. F. A. Influência dos fatores abióticos sobre a macrofauna de sbstratosinconsolidados as zona entre-marés no canal de Santa Cruz, Pernambuco, Brasil. Arquivo de Ciências do Mar, v. 38, p. 85-92, 2005.

PATRICK, W.S.; BENAKA, L.R. Estimating the economic impacts of bycatch in U.S. commercial fisheries. Marine Policy, v.38, p.470-475, 2013.

PEDROSA, L. F. C.; COZZOLINO, S. M. F. Composição centesimal e de minerais de mariscos crus e cozidos da cidade de Natal/RN. Revista Ciências e Tecnologia de Alimentos, Campinas, v. 21, n. 2, p. 154-157, 2001.

\section{PERSSON OSOWSKI, C.; GÔRANZON,H.;} FJELLSTRÔM, C. Teachers' interaction with children in the school meal situation: the example of pedagogic meals in Sweden. Journal of Nutrition Education and Behavoir, v.45, p.420-427, 2013.

PIGOTT, G.M.; TUCKER, B.W. Science opens new horizons for marine lipids in human nutrition. FoodRewiesInternational, v. 3, p. 105-138, 1987.

POSEY, D. A. Temas e inquirições em etnoentomologia: algumas sugestões quanto à geração de hipóteses. Boletim Museu Paraense Emilio Göeldi, v. 3, n. 2, p. 99-134, 1987.

REDE BRASILEIRA DE ALIMENTAÇÃO E NUTRIÇÃO ESCOLAR- REBRAE. Alimentação Escolar. Disponível em: <http://www.rebrae.com.br/alimentacao.html> Acesso em: 20 Jul. 2013.

RIOS, E. C. Seashells of Brasil. 2. ed. Rio Grande, RS. Editora da fundação Universidade do Rio grande, 1994.

SANTOS, A. M. L. A qualidade do pescado e a segurança alimentar. In: Simpósio de Controle do Pescado (SIMCOPE), 2., 2006, São Vicente, SP. Disponível em: 
ftp://ftp.sp.gov.br/ftppesca/qualidade_pescado.pdf. Acesso em: 3 de fev. 2010.

SANTOS, L. A.; FERES, S. J. C.; LOPES, A. T. L. Fauna de Bivalves da Praia de Panaquatira, Ilha De São Luís - MA . In: Congresso de Ecologia do Brasil, 8., 2007, Caxambu, MG. Disponível em: http://www.sebecologia.org.br/viiiceb/pdf/1024.pdf Acesso em: 18 de dez. 2009.

SANTOS-FITA, D.; COSTA-NETO, E.M. A interação entre os seres humanos e os animais: a contribuição da etnozoologia. Biotemas, v. 20, n. 4, p. 99-110, 2007.

SCHAEFFER-NOVELLI, Y. Manguezal: ecossistema entre a terra e o mar. São Paulo: CaribbeanEcologicalResearch, 1995.

SCHAEFFER-NOVELLI, Y.; CITRÓN-MOLERO. G. Brazilian mangroves: a historicalecology. Jornal Ciência e Cultura, v.51, p. 274-286, 1999.

SOUTO, F. J. B.; MARTINS, V. S. Conhecimentos etnoecológicos na mariscagem de moluscos bivalves no manguezal do distrito de Acupe, Santo Amaro-BA. Biotemas, v. 22 , n. 4 , p. 207-218, 2009.

SOUZA, R. S. Etnobotânica e etnozoologia de comunidades pesqueiras da área de proteção ambiental (APA) do Delta do Parnaíba, nordeste do Brasil. 2010. 178 f. Dissertação (Mestrado em Desenvolvimento e Meio Ambiente) Universidade Federal do Piauí, Teresina, 2010.

STANSBY, M.E. Polynsaturates and fat in fish flesh. Journal American Dietetic Associantion, v.63, p. 625-30, 1973.

STORER, T. I., et al. Zoologia geral. 6. ed. São Paulo: Companhia Editora Nacional, 2003.

VINCENZIA, M. A.; BARRERA-ARELLANO, D.; TRAMONTE, V. L. C. G. Composição lipídica do molusco marinho berbigãoAnomalocardia brasiliana (Gmelin, 1791) "in natura" e cozido. ArchivosLatinoamericanos de Nutricion. v. 59, n. 3, p. 337-341, 2009.

WHITFIELD, A. K. Ichthyofaunal assemblages in estuaries: a South African case study. Reviews in Fish Biology and Fisheries. v. 9, p. 151-186, 1999. 